\title{
Design of a Low Cost Compact Elliptic Function LPF Using Open Circuited Stubs
}

\author{
Sarbani Sen*, Tamasi Moyra \\ Department of Electronics and Communication Engineering, National Institute of Technology, Agartala 799046, West Tripura, \\ India
}

Corresponding Author Email: sensarbani77@gmail.com

https://doi.org/10.18280/ama_c.740105

Received: 31 December 2018

Accepted: 7 March 2019

\section{Keywords:}

lowpass filter, open circuited stubs, stepped impedance resonator, insertion loss, roll-off factor

\begin{abstract}
A miniaturized microstrip lowpass filter with low insertion loss and wide attenuation band is presented in this study. The filter is designed using two open circuited stubs and six stepped impedance resonators aligned symmetrically. The insertion loss in the passband varies from -0.049 to $-0.5 \mathrm{~dB}$. The proposed lowpass filter has $3 \mathrm{~dB}$ cut-off frequency at 3 $\mathrm{GHz}$ and the stopband region is extended from $3.59 \mathrm{GHz}$ to $14 \mathrm{GHz}$ with an attenuation level of $-15.5 \mathrm{~dB}$. The roll-off factor for the proposed filter is $56 \mathrm{~dB} / \mathrm{GHz}$ and the relative stopband suppression achieved is up to $130 \%$. Hence, the presented filter structure operating in S-band can be used in multiple applications like radar, WiMAX and other RF devices.
\end{abstract}

\section{INTRODUCTION}

In RF and microwave communication, lowpass filters those have the features of compact size, sharp roll off and wide attenuation band are in high demand [1-2]. Such highperformance devices are commonly used in mixers, amplifiers and oscillators to block unwanted high frequency harmonics. The popular technique to design a microstrip lowpass filter (LPF) is the use of stepped impedance lines or high-low impedance lines [3-5]. These commonly used techniques provide poor cut-off response, very low rejection level of insertion loss (IL) and narrow stop band. Usually, there are two significant steps to design a conventional microstrip LPF, first one is selecting an appropriate lowpass prototype and the other is finding a microstrip realization [6-7]. But such traditional structures offer gradual fall at $-3 \mathrm{~dB}$ cut-off and high insertion loss. To improve the sharpness, more sections should be cascaded which will increase the circuit size. Another way to enhance the performance of the conventional stub line filters is by replacing connected lines with slow wave resonators. Generally, modern microstrip lowpass filters are designed using either hairpin shape resonator or L-shape resonator [810]. But these resonators usually exhibit narrow stopband characteristics. To improve the attenuation band performance input/output feed lines can be cross coupled for introducing additional transmission zeroes. Inclusion of defected ground structures (DGS) in the circuit is another way of improving the stop band performance [11-12]. A sharp roll-off factor while maintaining a minimum insertion loss is an important parameter to implement any microwave filter [13-16]. In case of LPF using coupled lines [17], the capacitance of the coupled lines is too small and hence the finite attenuation poles cannot be located close to the passband. This results in gradual fall of cut off frequency response leading to a narrow attenuation band.

This work proposes a compact, low cost lowpass filter with low insertion loss and extended attenuation band. The filter prototype is modelled based on elliptic function response which provides infinite attenuation at finite frequencies. In order to obtain higher cut-off rate, the LPF is implemented using multiple open stubs which represent reactive elements. It is a generalized Chebyshev filter model of fourteen degree which introduces finite-frequency attenuation poles. The LPF is designed to have a cut-off frequency of $3 \mathrm{GHz}$ and it possess minimum insertion loss of $0.049 \mathrm{~dB}$ and maximum insertion loss of $0.5 \mathrm{~dB}$. The stopband suppression is up to $-15.5 \mathrm{~dB}$ and it ranges up to $14 \mathrm{GHz}$. Hence, the obtained relative stop bandwidth (RSB) is $130 \%$ with a suppression factor (SF) of 1.5. The roll factor is found to be $56 \mathrm{~dB} / \mathrm{GHz}$. In this study, the proposed microstrip LPF is designed and fabricated on FR4 substrate with a height $(\mathrm{h})$ of $0.8 \mathrm{~mm}$, a dielectric constant $\left(\epsilon_{\mathrm{r}}\right)$ of 4.4 , conductor thickness $(\mathrm{t})$ of $0.04 \mathrm{~mm}$ and loss tangent $(\delta)$ of 0.02. Eventually, the lumped equivalent circuit for the presented microstrip structure is proposed and the responses are compared accordingly. The LC values of the circuit are found by observing the attenuation poles and also optimized as per requirement. Finally, the EM simulated and measured responses are compared for experimental verification. There is a good agreement found between the predicted and measured results.

\section{FILTER DESIGN}

The design flow of the proposed lowpass filter structure begins with the microstrip realization followed by extraction of lumped equivalent circuit. Microstrip is chosen for the ease in fabrication.

\subsection{Microstrip structure}

Figure 1(a) shows the microstrip layout of the proposed lowpass filter. The filter comprises of two open-circuited stubs and six stepped impedance resonators parted by high impedance connecting lines. The physical lengths and widths of the presented structure is optimized to obtain the cut-off 
frequency at $3 \mathrm{GHz}$. Figure 1(b) shows the scattering parameters of the proposed LPF.

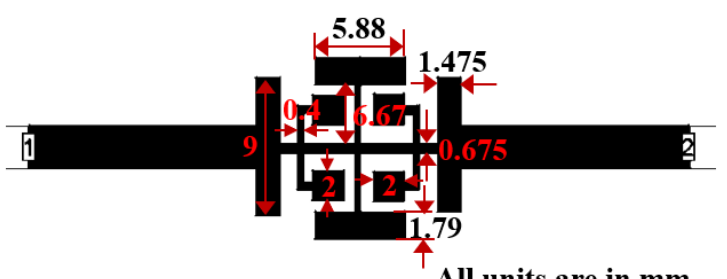

(a)

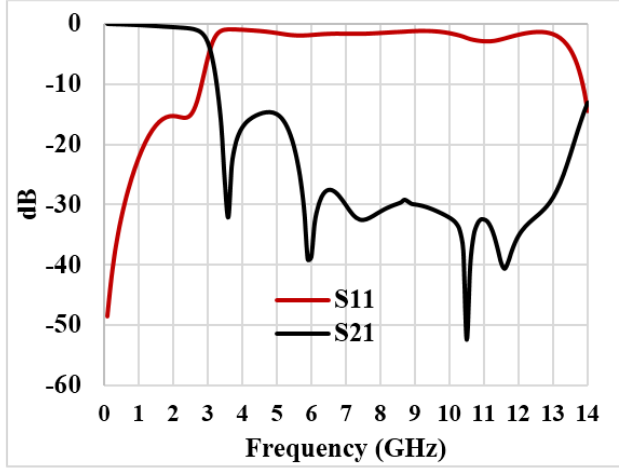

(b)

Figure 1. (a) Layout of proposed LPF (b) Scattering response of the filter

\subsection{Comparison of conventional stepped impedance vs. proposed LPF}

Figure 2(a) shows the conventional third order filter of 3 $\mathrm{GHz}$ cut-off frequency and Figure 2(b) depicts the comparison between the frequency responses of conventional LPF vs. proposed LPF. The conventional LPF suffers from gradual roll-off and poor attenuation band performance. To achieve sharp roll-off factor, the filter order should be increased. This will not only increase the circuit size but it will introduce additional insertion loss in the passband. To achieve high performance in smaller circuit area, the proposed LPF is designed. The physical lengths and widths of the conventional LPF can be obtained by using following formulas [7]:

$$
\begin{aligned}
& l_{l i}=\frac{\lambda_{g l} f_{c}}{2 \Pi} \operatorname{Sin}^{-1}\left(2 \pi f_{c} \frac{L_{i}}{Z_{o l}}\right) \\
& l_{c i}=\frac{\lambda_{g c} f_{c}}{2 \Pi} \operatorname{Sin}^{-1}\left(2 \pi f_{c} Z_{o c} C_{i}\right)
\end{aligned}
$$

where, $\lambda_{g l}$ and $\lambda_{g c}$ are the guided wavelengths of the hi-low lines, $f_{c}$ is the cut-off frequency. $L_{i}$ and $C_{i}$ are the inductance and capacitance of the third order lowpass filter. It can be found by [7]:

$$
\begin{aligned}
& L_{i}=\frac{1}{2 \pi f_{c}} Z_{0} g_{l i} \\
& C_{i}=\frac{1}{2 \pi f Z_{c} Z_{0}} g_{c i}
\end{aligned}
$$

where, $Z_{0}=50 \Omega, g_{l i}$ and $g_{c i}$ denotes the inductive and capacitive elements [7]. Here, $i=1,2,3,4,5$.

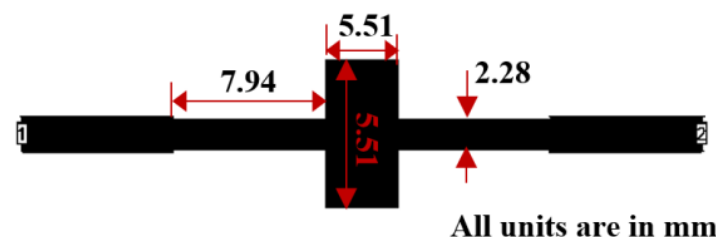

(a)

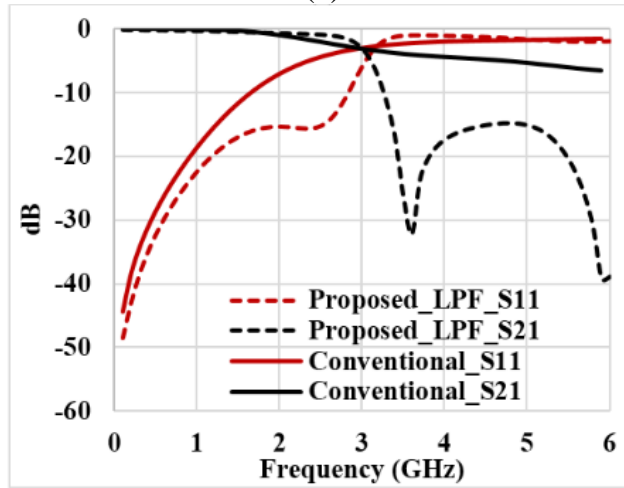

(b)

Figure 2. (a) Layout of conventional stepped impedance LPF (b) Frequency response of stepped impedance vs. proposed LPF

\subsection{Equivalent circuit}

The lumped equivalent circuit for the proposed lowpass filter can be obtained by using Eq. (3-4). Figure 3(a) shows the LC-equivalent circuit of the microstrip LPF and the frequency response is shown in Figure 3(b). The two-port network is terminated by $50 \Omega$ impedance lines at either ends.

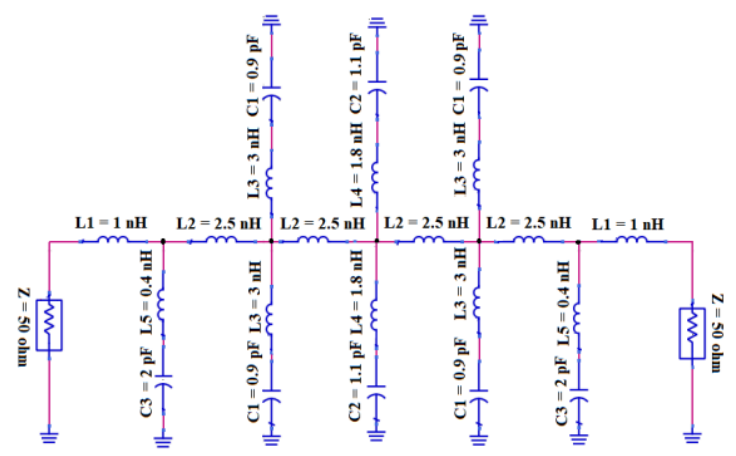

(a)

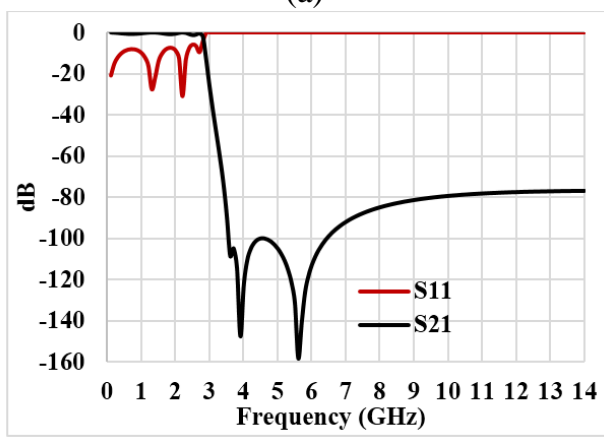

(b)

Figure 3. (a) Lumped equivalent circuit of the proposed LPF (b) Circuit simulated response 


\subsection{Current distribution}

The current distribution with respect to frequency is shown in Figure 4. The current magnitude is highest at the cut-off frequency and lower at all other frequencies. It is observed that the LPF segments possesses more current at lower range of frequencies and gradually diminishes at the higher end (e.g. 7 $\mathrm{GHz}$ ). This signifies that the structure is active at lower frequencies and the current flowing through the structure is unidirectional.

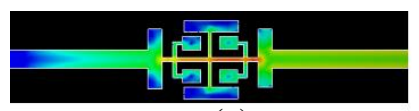

(a)

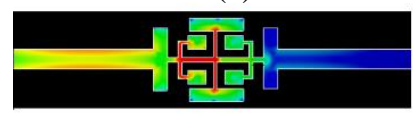

(c)

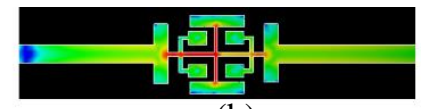

(b)

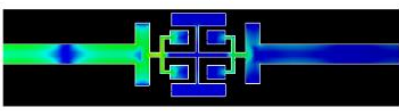

(d)
Figure 4. Current distribution at (a) $0.5 \mathrm{GHz}$ (b) $2.4 \mathrm{GHz}$ (c) $3 \mathrm{GHz}$ and $(\mathrm{d}) 7 \mathrm{GHz}$

\subsection{Filter characteristics}

The proposed filter has the minimum insertion loss of $0.049 \mathrm{~dB}$ and maximum insertion loss of $-0.5 \mathrm{~dB}$. The roll-off factor can be obtained by:

$$
\xi=\frac{\alpha_{\max }-\alpha_{\min }}{f_{s}-f_{c}} \quad(\mathrm{~dB} / \mathrm{GHz})
$$

where, $\alpha_{\max }$ is the $40-\mathrm{dB}$ attenuation point and $\alpha_{\min }$ is the $3-\mathrm{dB}$ attenuation point; $f_{s}$ is the $40-\mathrm{dB}$ stopband frequency and $f_{c}$ is the $3 \mathrm{~dB}$ cut-off frequency. The calculated roll-off factor for the proposed LPF is $56 \mathrm{~dB} / \mathrm{GHz}$.

The relative stop bandwidth (RSB) is defined as:

$$
R S B=\frac{\text { StopBandwidth }}{\text { StopBandCenterFrequency }}
$$

It is found that the relative stop band suppression is achieved up to $130 \%$ i.e. the RSB is 1.3 . The suppression factor (SF), i.e. suppression/10 dB is found based on the average harmonic suppression in the stop band which is approximately 1.5 . The normalised circuit size (NCS) is obtained by:

$$
N C S=\frac{\text { PhysicalSize }(\text { length } \times \text { width })}{\lambda_{g}^{2}}
$$

where, $\lambda_{g}$ is the guided wavelength at $3 \mathrm{~dB}$ cut-off frequency. The size of the proposed filter is $(13.46 \times 12.03) \mathrm{mm}^{2}$, which corresponds to $0.24 \lambda_{g} \times 0.21 \lambda_{g}$.

\section{FABRICATION AND MEASUREMENT}

The presented lowpass filter is fabricated and measured. The pictorial view of the fabricated structure is shown in Figure 5(a). The measured data vs. simulated data are plotted and shown in Figure 5(b). There is a good agreement obtained between the measured and simulated results. The proposed lowpass design has a wide attenuation band up to $14 \mathrm{GHz}$ with a suppression level of $-15.5 \mathrm{~dB}$. It is fabricated using low cost FR4 substrate. Figure 5: (c) shows the group delay undergone by the LPF and it can be calculated as:

$$
\text { Group delay }=-(\Delta \emptyset) / \Delta \omega \quad \text { and } \omega=2 \pi f
$$

where ' $\varphi$ ' is phase angle of S21 and ' $\omega$ ' is the angular frequency whose unit is $\mathrm{rad} / \mathrm{sec}$.

It is projected that a filter should produce flattest group delay in the passband. The proposed LPF structure exhibits almost flat delay in the passband region. The average group delay in the passband is $0.00078 \mathrm{~ns}$.

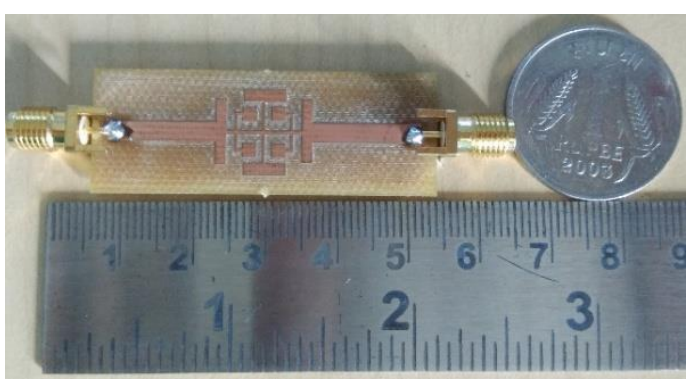

(a)

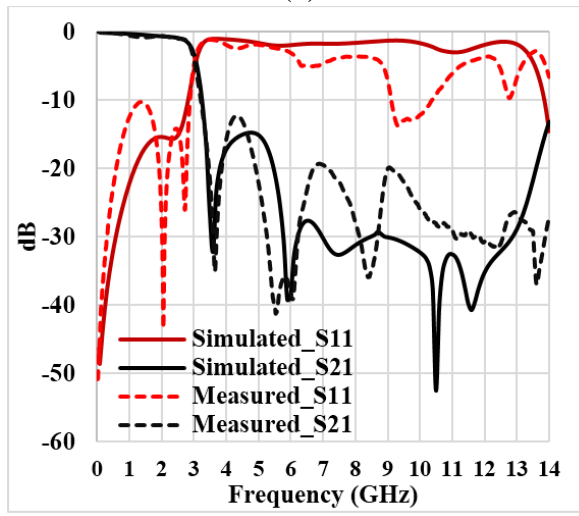

(b)

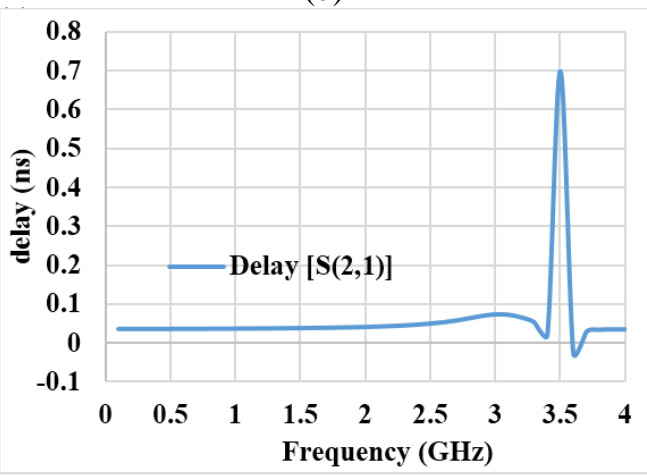

(c)

Figure 5. (a) Fabricated LPF structure (b) EM simulated response vs. measured response (c) Group delay

The performance comparison of the proposed work with the existing works are shown in Table 1.

The structures proposed in ref. [4] and ref. [14] are smaller in size but they exhibit poor stopband performance compared to the rest. An excellent attenuation band performance is achieved in ref. [15], but the roll-off (RO) factor is low. Similarly, the circuit recemmended in ref. [5], exhibits poor roll-off, larger size and narrow stopband. The proposed filter is not only designed using cheap substrate material but also provides sharp roll-off and wider attenuation band. 
Table 1. Comparative analysis of the proposed work with the existing work

\begin{tabular}{|c|c|c|c|c|c|}
\hline Ref. & $\begin{array}{c}\text { Dielectric } \\
\text { material }\end{array}$ & $\begin{array}{c}f_{\mathbf{c}} \\
(\mathbf{G H z})\end{array}$ & $\begin{array}{c}\text { RO } \\
\text { (dB/G } \\
\text { Hz) } \\
\end{array}$ & $\begin{array}{c}\text { Size } \\
\left(\lambda_{\mathrm{g}} \times\right. \\
\left.\lambda_{\mathrm{g}}\right) \\
\end{array}$ & $\begin{array}{c}\text { Stopband } \\
\text { suppression }\end{array}$ \\
\hline [4] & $\begin{array}{c}\text { RT/Duroi } \\
\text { d } 5880\end{array}$ & 1.5 & 36 & $\begin{array}{c}0.037 \\
\times \\
0.093\end{array}$ & $\begin{array}{l}-10 \mathrm{~dB} \text { up } \\
\text { to } 15 \mathrm{GHz}\end{array}$ \\
\hline [5] & FR4 & 2.4 & 36 & $\begin{array}{c}0.35 \times \\
0.2\end{array}$ & $\begin{array}{l}-20 \mathrm{~dB} \text { up } \\
\text { to } 6 \mathrm{GHz}\end{array}$ \\
\hline [14] & $\begin{array}{c}\text { Roger } \\
\text { RO4003 }\end{array}$ & 0.85 & 23 & $\begin{array}{c}0.089 \\
\times \\
0.081\end{array}$ & $\begin{array}{l}-15 \mathrm{~dB} \text { up } \\
\text { to } 12.6 \mathrm{GHz}\end{array}$ \\
\hline [15] & $\begin{array}{c}\text { RT/Duroi } \\
\text { d } 5880\end{array}$ & 6 & 30 & NA & $\begin{array}{l}-29 \mathrm{~dB} \text { up } \\
\text { to } 60 \mathrm{GHz}\end{array}$ \\
\hline $\begin{array}{l}\text { This } \\
\text { work }\end{array}$ & FR4 & 3 & 56 & $\begin{array}{c}0.24 \times \\
0.21\end{array}$ & $\begin{array}{l}-15.5 \mathrm{~dB} \text { up } \\
\text { to } 14 \mathrm{GHz}\end{array}$ \\
\hline
\end{tabular}

\section{CONCLUSION}

In this paper, a compact, low cost lowpass filter is proposed using open stubs and stepped impedance resonators. The LPF is designed to operate in S-band with a cut-off frequency of 3 $\mathrm{GHz}$. Additional poles are generated by introducing the stepped impedance resonators. The structure is fabricated using low cost material and measured for experimental validation. The stopband suppression level of $-15.5 \mathrm{~dB}$ is achieved up to $14 \mathrm{GHz}$ and the maximum insertion loss in the passband is $-0.5 \mathrm{~dB}$. The performance of the filter can still be improved by using low loss substrate in the future. The stopband suppression is achieved up to fourth harmonic. With this good performance, the proposed lowpass filter can be used in various applications like RADAR, WiMAX and other communication systems.

\section{ACKNOWLEDGMENT}

Authors are thankful to Mr. Dipesh Debnath, National Institute of Technology, Agartala, Tripura, India and Dr. Santanu Dwari, Indian Institute of Technology, Dhanbad, Jharkhand, India for their support.

\section{REFERENCES}

[1] Mohra, A.S., Alkanhal, M.A. (2007). Small size stepped impedance low pass filters. Microwave and Optical Technology Letters, 49(10): 2398-2403. http://doi.org/10.1002/mop.22766

[2] Shaman, H., Almorqi, S., AlAmoudi, A. (2015). Composite microstrip lowpass filter with ultrawide stopband and low insertion loss. Microwave and Optical Technology Letters, 57(4): 871-874. http://doi.org/10.1002/mop.28981

[3] Cho, J.H., Lee, J.C. (2006). Microstrip steppedimpedance hairpin resonator low-pass filter with defected ground structure. Microwave and Optical
Technology Letters, 48(2): 405-408. http://doi.org/10.1002/mop.21364

[4] Yang, M.H., Xu, J. (2008). Design of compact, broadstopband lowpass filter using modified stepped impedance hairpin resonators. Electronics Letters, 44(20): 1198-1199. http://doi.org/10.1049/el:20081875

[5] Sen, S., Moyra, T., Sarkar, D. (2018). Modelling and validation of microwave LPF using modified rectangular split ring resonators (SRR) and defected structures. International Journal of Electronics and Communication (AEÜ), 88:

$1-10$. http://doi.org/10.1016/j.aeue.2018.02.009

[6] Chen, W.K. (1986). Passive and active filters. John Wiley.

[7] Hong, J.S., Lancaster, M.J. (2001). Microstrip Filters for RF/Microwave Applications. John Wiley \& Sons. Inc. (Hardback); 0-471-22161-9 (Electronic); [ISBNs: 0-47138877-7].

[8] Jahanbakhshi, M., Hayati, M., (2016). Design of a compact microstrip lowpass filter with sharp roll-off using combined T-shaped and L-shaped resonators. Electronics Letters, 52(23): 1931-1933. http://doi.org/10.1049/el.2016.3432

[9] Matthaei, G.L., Young, L., Jones, E.M.T. (1980). Microwave filters, impedance-matching network and coupling structures. Artech House, Norwood, MA.

[10] Yang, Y., Zhu, X., Karmakarl, N.C. (2011). Design of a novel microstrip lowpass filter for UWB chipless RFID readers. IEEE, Proceedings of the Asia-Pacific Microwave Conference, Melbourne, VIC, pp. 98-101.

[11] Liu, S., Xu, J., Xu, Z.T. (2015). Sharp roll-off lowpass filter using interdigital DGS slot. Electronics Letters, 51(17): 1343-1345. http://doi.org/10.1049/el.2015.0721

[12] Chen, Q., Xu, J. (2010). DGS resonator with two transmission zeros and its application to lowpass filter design. Electronics Letters, 46(21): 1447-1449. http://doi.org/10.1049/el.2010.2251

[13] Hayati, M., Akbari, M., Salahi, R. (2016). Compact microstrip lowpass filter with wide stopband and verysharp roll-off. Electronics Letters, 52(10): 830-831. http://doi.org/10.1049/el.2016.0191

[14] Cui, H., Wang, J., Zhang, G. (2012). Design of microstrip lowpass filter with ultra-wide stopband. Electronics Letters, $\quad 48(14)$ : 854-856. http://doi.org/10.1049/el.2012.1362

[15] Mirzaee, M., Virdee, B.S., (2014). Compact Lowpass Filter with High out-of-band Rejection and Super Wide Stopband Performance. Microwave and Optical Technology Letters, 56(4): 947-950. http://doi.org/10.1002/mop.28209

[16] Bhowmik, P., Moyra, T. (2018). Design of a cheap compact low-pass filter with wide stopband. Advances in Modelling and Analysis C, 73(1): 17-22. http://doi.org/10.18280/ama_c.730103

[17] Abbosh, A.M. (2012). Lowpass filter utilizing broadsidecoupled structure for ultrawideband harmonic suppression. IET Microwave. Antennas Propagation, 6(3): 276-281. http://doi.org/10.1049/iet-map.2011.0254 